NATURE

No. 3769

SATURDAY, JAN. 24, 1942

Vol. 149

\title{
CONTENTS
}

Science and Society

Page

Centralized Research in the Social Sciences :

The Case for Research in the Social Sciences. By Prof. George E. G. Catlin . . . . .

Biology as a Social Science. By Mrs. S. NevilleRolfe, O.B.E.

Impact of the Physical Sciences on Society. By Prof. J. A. Crowther . . . . .

Social Science, Statistics and Population Problems. By D. Caradog Jones

Ethical and Political Remodelling of Society. By Sir Frederic Kenyon, G.B.E., K.C.B., F.B.A.

Research in the History of Sociology. By Alexander Farquharson.. . . . . .

Decline and Revival of Acid-Base Catalysis Theory. By Prof. M. Polanyi . . . . . . . .

Historical Geography-Then and Now. By Dr. J. N. L. Baker

Romanticism and Science. By Prof. A. Wolf . .

News and Views . . . . . . . . 105

Letters to the Editors :

Excitation of Nematocysts.-Dr. C. F. A. Pantin, F.R.S. 109

Properties of Cuticle and Insect Ecology.-Dr. B. P.

Uvarov ; Dr. H. Kalmus . . . . . .

Difference in Resistance to Toxic Substances of Mutants of Drosophila of Different Body Colour. -Dr. H. Kalmus, Dr. J. T. Martin and C. Potter

A Ctenophore from the Palestinian Coast.-1. Haas Northern Fringe of the Palæolithic in England.Dr. H. N. Gibson

Names of Electrical Units.-Prof. Reginald O. Kapp Crystallization in an Inflated Rubber Balloon.Adolf Schallamach . . . . . . .

A Reversible Discharge Tube.-Dr. A. G. Gaydon . Research Items

The Predictive Method in Animal Ecology. By Dr.

D. Stewart Maclagan

Conditions in Factories

Reconstruction and Economics . . . . . 117

Editorial and Publishing Offices

MACMILLAN \& CO., LTD.

ST, MARTIN'S STREET, LONDON, W.C.2

Telephone Number: Whitehall 8831

Telegrams: Phusis Lesquare London

Advertisements should be addressed to

T. G. Scott \& Son, Ltd., Three Gables, London Road, Merstham, Surrey Telephone: Merstham 316

The annual su bscription rate is $\$ 4100$, payable in advance, Inland or Abroad All rights reserved. Registered as a Newspaper at the General Peot Office

\section{SCIENCE AND SOCIETY}

$\mathrm{M}$ UCH indeed has happened since Prof. J. R. Marrack in 1937 contributed his stimulating essay on the "Social Implications of Biochemistry" to the volume of essays "Perspectives in Biochemistry" which was presented to Sir Frederick Gowland Hopkins by past and present members of his laboratory on his seventy-fifth birthday. It is now widely realized that not only, as Prof. Marrack pointed out, does the future trend of biochemical investigation into problems of nutrition depend largely on what form society takes, but also the whole trend of scientific work or even thought. The impact of society on science is as unmistakable as that of science on society.

That recognition has already found expression in important developments both in the field of science itself and in the world of politics. We have seen the formation of a new Division of the British Association for the study of the social and international relations of science. Nuffield College, Oxford, has been established as well as the National Institute of Economic and Social Research. Although the stress laid on research in the Report of the Royal Commission on the Distribution of the Industrial Population has yet to be implemented, the proposal in the minority report for the establishment of a commission of research covering all matters-land, agriculture, minerals, amenities, etc.-affected by national development finds widespread support.

In the field of politics account has been increasingly taken of the new knowledge of nutrition in handling questions of food supply and food production during the War, and there is evidence that Government is prepared to face the questions involved in the provision of diet standards based on the biochemical work of the last thirty years, and at least implement the possibilities thus opened up of raising the standards of health of a large proportion of the people of Great Britain through the provision of an economic and better diet by expanding social services, and a determined attack on malnutrition and its causes. That much, at least, is implied in the conception of a social minimum now gaining support, and its application is by no means limited to the people of Great Britain. Its bearing on the questions of Colonial welfare and development and on the feeding of the people of the enemy-occupied territories after the War, as well as on European economic and social reconstruction, are equally to the fore. The formation of the Bureau under Sir Frederick Leith-Ross announced at the second meeting of the Inter-Allied Council in September is evidence that practical effect is being given to such ideas, and the American co-operation then indicated will assuredly not be withdrawn or diminished now that the United States has entered the War.

The most striking feature of all such developments is, however, the immense amount of ad hoc inquiry, investigation and research which is still required over the whole range of the social sciences as a basis for policy and action. It is this that raises such 
studies to the priority level even in war-time, if having won the War we are not once again to lose the Peace. Even in the field of internal reconstruction the same condition holds. Lord Reith has already indicated the importance he attaches to research in a statement on the work of his Department made as long ago as February last year, and Mr. Greenwood, the Minister in charge of reconstruction, has stressed the importance of such surveys as those of the whole field of social insurance and allied services including unemployment assistance and workmen's compensation which Sir William Beveridge has undertaken. Further, plans are being made for the Agricultural Economics Research Institute to conduct a survey of problems of agricultural reconstruction when the necessary funds are assured. Mr. Greenwood has referred particularly to the North-East Regional Reconstruction Group of which Prof. J. H. Jones is honorary secretary. This is only one of several regional reconstruction organizations. Also, there are the investigations of Political and Economic Planning, and particular importance is attached to the work of the Demographic Survey of the 1940 Council. Mass observation, too, makes valuable social surveys, though we believe its scope and the intensity of its work are rather limited compared with similar social surveys and observations frequently made in the United States.

It is clear, therefore, that the importance of social research is recognized by the Government and that the co-operation of other institutions and bodies, whether local or regional, industrial or professional, is welcomed as leading to the development of new technique. Despite these numerous activities it also appears that not only is some real co-ordination and central guidance desirable but also much more effective financial support. In the absence of greatly extended Government assistance there is no evidence that many of these activities will be able to make more effective contributions than the Social Science Department or Economics Research Section of those Universities like Manchester and Liverpool which have already entered the field of social economics.

It is no disparagement of the work which has been carried out by such departments or by the National Institute of Economic and Social Research to suggest that with extended financial resources they might already have made much more important contributions to the solution of social problems of national and not merely local importance. This question of finance, with the further question of objective research, is in fact the vital one to consider in judging the proposal recently advanced by Prof. George Catlin in a letter in The Times of December 22, although regard should be had to the general background already outlined. The urgency of the need for more intensified research in the social sciences and a scientific examination of the impact of science upon society has been repeatedly stressed in NATURE over the last decade or so. A more biological approach is also an urgent need in the study of local, national and international policies, as is well argued by Mrs.
Neville-Rolfe on p. 90-a thesis which she and others have been urging for some time past.

Prof. Catlin expresses his regret that the opportunity was lost ten years ago of establishing a social science research council as a genuine academic council representative of all branches of the social sciences in Great Britain. Such a scheme involving the survey of projects for research, the allocation of financial assistance and aid in personnel for the prosecution of such research and the direction of endowments into fields the probable fertility of which had been explored, would have done more than augment the resources of the struggling university departments or other research organizations. It would have provided an organ for an authoritative voice of the social sciences and immensely strengthened their position in respect of objective research.

On p. 88 Prof. Catlin urges strongly that the establishment of a representative social science body, of the highest academic standing and the fullest professional knowledge, that can freely express itself in a fashion that will command attention within this sphere is required to avoid the natural limitations of the Royal Society and the British Association with regard to social science. Such a body could have corrected many false conclusions in the past and could assist the Government and public authorities in many directions likely to be of paramount importance. Moreover, long-range work under such a council in fields, for example, like economic reconstruction and population studies, would be beyond suspicion of political bias.

This latter point is probably of the more importance since there is a sense in which the scientific work and thought which are required to provide the material which will enable social structures to be designed with full knowledge by Governments and administrators inevitably involves entering the political field. This, as Sir Richard Gregory has pointed out, is another matter from political partisanship, and provided the functions of the expert and the administrator are not confused there is no justification for the fear of science becoming entangled in contraversial politics presenting a bogy to the advance of the social sciences by the application of impartial scientific methods and principles to the problems involved in them. Indeed, Prof. A. V. Hill, in supporting Dr. Catlin's proposal, has suggested that the Royal Society might help, as it helped in establishing the British Academy in 1902, and while urging the application of the results of science to human betterment has uttered a warning against allowing our desire for betterment to upset our scientific conclusions or bias our scientific judgments.

Prof. Catlin's proposal has also been warmly welcomed in the correspondence columns of The Times by Mr. F. S. Stone, acting secretary of the National Institute of Economic and Social Research, who, indicating the willingness of the Institute to cooperate, points out that the Council of the Institute does not attempt or claim to cover many important branches of the social sciences such as anthropology and social psychology, although as Mr. Charles Madge 
has pointed out, the Council of the Institute is potentially the social research council for which Prof. Catlin asks. We take the view, however, that research in the social sciences to be effective must cover a much wider field-in fact, it must invoke the aid of almost every branch of science. We cannot, therefore, subscribe to Mr. A. Farquharson's view, expressed on p. 101, that "the narrower field [of sociology] may be appropriate as defining a useful field of operations for the present and that the wider view should not be dropped altogether out of sight". We envisage a much wider basis for the proposed activities, and this is illustrated by the other articles published in this issue. The foundation should be as broad and comprehensive as possible if the proposed organization is not to make the grave error of following a too narrow and specialized path. The President and Honorary Secretary of the Royal Anthropological Institute have also supported the proposal and indicated the willingness of that Institute to cooperate. Moreover, in their letter they stress the urgency of the need for such action.

The need for some kind of central research organization with adequate resources at the present time appears to be generally accepted, though the exact manner in which this need should be met gives rise to some difference of opinion. Prof. Abercrombie, stressing the need for scientific research into population problems, family units, industrial location, quality of farmland, transport, etc., with reference to planning for reconstruction, has suggested reconsideration of the proposal in the Minority Report of the Barlow Commission for a permanent commission of research as another alternative to the social research council worth examining.

The articles published in this issue of Nature indicating the need for research in the various branches of sociology leave no room for doubt as to the imperative necessity of some such step. A much more generous endowment of such research through Government grants and the great foundations and trusts is to be hoped for to redress the disparity between our research effort in the biological and social sciences and in the physical sciences and to check the dangerous gaps arising through the unevenness of the whole research front.

The present proposals very clearly cannot be considered altogether without regard to the present structure and organization of scientific research as a whole in Great Britain. Moreover, there is some difference of opinion among our contributors as to the exact form of the organization required, and some clarification of thought as to the functions which it should serve must precede the establishment of any new body. Sir Frederic Kenyon, for example, visualizes some organization on the lines of the Royal Institute of International Affairs or of the Institute of Chemistry, for the collection of facts and the formation of opinion or formulation of principles in social science. Mrs. S. Neville-Rolfe suggests rathor the formation of an Institute able to act in a consultative-directive capacity. On the desirability of a central research institu- tion competent to attract investigators of distinction, to encourage co-ordination and concorted planning there is g.neral agreement. Adequately financed and staffed and ably directed, such a central research organization, through its various departments briefly envisaged in the following articles, could make an immense contribution to the wise and effoctive use of our resources both in war and in peace.

There seems to us a grave risk involved in the suggestion that a Social Sciences Research Council be established along lines similar to those of the Agricultural and the Medical Research Councils. The ramifications of the social sciences go much farther and involve a larger number of special sciences than either of the other two, which are naturally confined to more or less well-defined though limited fields of action. Furthermore, these two already existing Councils have great assets in research personnel and accommodation for medical and agricultural research already existing in the universities, colleges and institutes throughout Great Britain. This csnnot be said for the social sciences. Most of the special sciences become involved in sociology. Some receive attention from the point of view of their impact on society; but this only in certain universities and the various institutes already existing for the purpose which are specialized or are very narrow in their terms of reference. In the case of the social sciences, therefore, it seems that what is most desirable is the formation of a central institute with a permanent staff where research could be carried out or organized and deputed to university or other centres which already have the necessary staff and material. Research should be the key-note of the organization of such an institute; data would be gathered, sifted and corrolated; funds administered; information supplied; and courses of lectures, refresher courses and vacation schools organized.

Platforms for the expression of points of view, for symposia on the social sciences and for discussions concerning the impact of science on society already exist and have done and are doing useful work. Almost every section of the British Association, for example, discusses in some way or another the social implications of its own particular scientific discipline, and the Division for the Social and International Relations of Science, under the chairmanship of Sir Richard Gregory, has already done work of inestim. able value along these lines. Then there are the other more limited institutions and societies. But all these exist chiefly for the expression of points of view and for the determination of policy. Only within very narrow limits can they be expected actively to carry out research, and it is research in the social sciences which is so urgently needed. For this, some new form of central organization is, without doubt, badly needed, and now is the time for its foundation. Problems peculiar to war-time would receive prior claim, and thus would be laid a sure foundation for the development of the organization after the War, so that science could play a more practical part in the establishmint and keeping of that kind of peace for which evcryone is hoping. 